\title{
Effect of Intraluminal Flow on Proximal
}

\section{Tubular Reabsorption}

\author{
Ettore Bartoli, John D. Conger, and Laurence E. Earley \\ From the Departments of Medicine and Physiology and the Cardiovascular \\ Research Institute, University of California San Francisco, \\ San Francisco, California 94122
}

\begin{abstract}
A в S T R A C T Micropuncture techniques in the rat were used to reinvestigate the possibility that intraluminal flow rate per se may influence net volume reabsorption by the proximal tubule. An experimental design was devised which lowered intraluminal flow without affecting filtration rate of the nephron under study or without directly affecting other renal hemodynamics. In 11 rats flow of tubular fluid between early and late proximal tubular sites was reduced by partially collecting tubular fluid at the early puncture site. In 42 nephrons the rate of flow of tubular fluid was reduced an average of $45 \%$ without changing nephron filtration rate and there was an associated reduction in reabsorption between the two sites which averaged $29 \%$. This indicated $63 \%$ balance between delivery of tubular fluid and the rate of reabsorption between two sites along proximal tubules. The results of these studies indicate that a reduction in delivery of normal filtrate along the proximal tubule is associated with a concordant reduction in the absolute rate of reabsorption. Since this relationship occurred in the absence of changes in renal hemodynamics or even a change in filtration rate of the nephron under study it is concluded that changes in intraluminal load per se play an important role in the phenomenon of glomerulotubular balance.
\end{abstract}

\section{INTRODUCTION}

The phenomenon known as glomerulotubular balance has been the subject of frequent investigations with micropuncture techniques during the past several years. It has been demonstrated that when glomerular filtration rate is reduced experimentally by a variety of maneuvers a nearly proportionate fall occurs in the rate of proximal tubular reabsorption, accounting for a major

Received for publication 18 September 1972 and in revised form 5 December 1972. portion of the overall balance between filtration and reabsorption. Several theories have been proposed to explain glomerulotubular balance. Kelman (1) suggested that the proximal tubule behaves as a catalytic flow reactor and that the radial diffusion of sodium from proximal tubular lumen across apical cell membranes is a limiting step in transtubular sodium transport. According to this concept when filtration rate is decreased turbulence within the lumen would diminish and net diffusion of sodium from luminal fluid into cells would fall, thereby decreasing net reabsorption. This concept seems unacceptable since it is unlikely that flow within the lumen of the renal tubule is turbulent or that radial diffusion of sodium is limiting step in net reabsorption. Leyssac (2) proposed that glomerulotubular balance is the result of an intrarenal hormonal feedback loop involving the renin-angiotensin system. Decreases in delivery of tubular fluid to the macula densa. as would result from a fall in filtration rate, cause a release of renin and subsequent formation of angiotensin in the area of the afferent arteriole. Angiotensin would then gain access to renal tubules by way of the glomerular filtrate or the peritubular circulation and it was envisioned that angiotensin depresses the rate of tubular reabsorption of sodium. Although this mechanism has not been disproved directly, it does seem unlikely in view of recent evidence that complete interruption of flow of tubular fluid out of proximal tubules has no apparent effect on reabsorption (3). ${ }^{1}$ Gertz, Mangos. Braun, and Pagel (4) proposed that the degree of distension of proximal tubules, presumably by influencing surface area, regulates the rate of reabsorption. This was based on circumstantial evidence that under a variety of conditions there is a direct relationship between

${ }^{1}$ Bartoli, E., and L. E. Earley. An apparent effect of tubular fluid flow on nephron filtration rate. Submitted for publication. 
intratubular volume and the rate of reabsorption (5). However, this concept cannot account for the presence of glomerulotubular balance when filtration rate is lowered by ureteral or renal venous obstruction which produce tubular distension at a time when reabsorption is decreased $(6,7)$.

Each of the above explanations for glomerulotubular balance involves some intraluminal effect of changes in the delivery of filtrate to bring about concordant changes in the rate of reabsorption. However, most of the experimental designs used to study the phenomenon produce additional effects such as changes in blood flow, filtration fraction, and hydrostatic pressure which could mediate the change in tubular reabsorption. Techniques for microperfusing individual tubular segments and measuring reabsorptive rates afford a means of directly examining the effect of changing intratubular load on the rate of reabsorption. Although early studies with this technique -were interpreted as showing a direct relationship between intratubular load and reabsorptive rate (8) several recent studies employing tubular perfusion in vivo (9-11) or in vitro (12) showed either no influence or only a limited influence of perfusion rate on reabsorptive rate. Moreover, it has been shown that a reduction in renal perfusion pressure and whole kidney filtration rate results in a fall in reabsorption by proximal tubules in which the intratubular load was maintained by microperfusion (13). Thus, the majority of evidence obtained from microperfusion of tubular segments indicates that glomerulotubular balance is not mediated by an intraluminal effect of load (glomerular filtrate) per se.

During the same period of time that the phenomenon of glomerulotubular balance was being studied as outlined above, a considerable body of evidence was being accumulated supporting the view that forces determining peritubular capillary absorption also may regulate proximal tubular reabsorption $(14,15)$. Such evidence together with the lack of experimental support for an intraluminal pathway mediating glomerulotubular balance has shifted attention to peritubular capillary forces as a mechanism for coupling filtration rate and tubular reabsorption (16-20). Changes in filtration fraction which could occur when filtration rate is changed could modulate peritubular flasma protein concentration in such a way as to effect proportionate changes in tubular reabsorption (16-18). Alternatively, decreases in peritubular blood flow accompanying decreases in filtration rate conceivably could limit peritubular capillary absorptive capacity and decrease net tubular reabsorption $(13,16$, 17).

In this laboratory we recently reinvestigated proximal tubular reabsorption using the technique of in vivo microperfusion (21). Our data suggested that proximal reabsorption is influenced by nonidentified plasma fac- tors and that difficulties inherent to the technique do not allow precise recognition of flow mediated changes in reabsorption, although this was supported by the evidence.

For the above reasons it seemed important to reinvestigate the possibility that there does exist some direct relationship between intraluminal load per se and the rate of proximal tubular reabsorption. Accordingly, a method was devised for changing the delivery of normal glomerular filtrate in individual nephrons without involving hemodynamic changes in the kidney and without changing filtration rate of the nephron under study. The results indicate that there is a major decrease in reabsorption when load is diminished under such circumstances indicating that intraluminal factors can play an important role in glomerulotubular balance.

\section{METHODS}

Experiments were performed in 11 male Sprague-Dawley rats weighing $250-350 \mathrm{~g}$ which were anesthetized and prepared for micropuncture as described previously (3). Animals received a maintenance infusion of an isotonic Ringer's solution at $50 \mu \mathrm{l} / \mathrm{kg}$ per $\mathrm{h}$ which contained inulin in an amount to maintain plasma levels of $50-100 \mathrm{mg} / 100 \mathrm{ml}$ and $p$-aminohippuric acid in an amount appropriate for clearance measurements. Techniques for micro- and macroanalyses were the same as described previously $(3,14)$. Means of results are expressed as \pm 1 standard deviation. Significance of differences between means was tested by paired or unpaired $t$ test or by variance analysis (22).

Reduction in intraluminal flow by double collection was performed in 42 tubules of 11 rats. The technique is shown schematically in Fig. 1. A thin and long-tipped pipette (pipette 1, OD 6-8 $\mu \mathrm{m}$ ) filled with oil was inserted into what appeared to be an early proximal convolution (site $a$ ) and an oil droplet was injected for purposes of mapping the more distal surface convolutions. A second pipette (pipette 2, OD $10 \mu \mathrm{m}$ ) was inserted into the most distal surface convolution (site $b$ ) of the same proximal tubule. With both pipettes in place a total free flow collection was taken by the usual technique (3) from site $b$ (collection 1). A new pipette was then inserted at site $b$ and after inserting the oil block for total collection at site $b$ simultaneous collections were begun at both sites $a$ and $b$ (collection $2 a$ and $2 b$ ). Removal of tubular fluid at site $a$ was controlled, usually by applying positive pressure, so as to remove at a steady rate only a portion of the tubular fluid passing site $a$. Aspiration at site $b$ was performed to collect all of the remaining tubular fluid. The duration of this double collection was 3-14 min. A final collection (collection 3 ) was made by inserting a new pipette at site $a$ and aspirating all tubular fluid reaching this site.

Nephron filtration rate (NFR) ${ }^{2}$ was calculated from the tubular fluid (TF) to plasma (P) ratio for inulin (In) and the volume of tubular fluid collected per unit time (V):

$$
\mathrm{NFR}=\mathrm{V}\left(\mathrm{TF} / \mathrm{P}_{\mathrm{In}}\right) \text {. }
$$

${ }^{2}$ Abbreviations used in this paper: $\mathrm{C}$, tubular reabsorption; D, tubular fluid flow rate; In, inulin; NFR, nephron filtration rate; $\mathrm{P}$, plasma; $\mathrm{TF}$, tubular fluid; $\mathrm{V}$, volume collected per unit time. 
The absolute rate of tubular reabsorption (C) was calculated as NFR - V. During double collections NFR was taken as the sum of NFR calculated from collections at sites $a$ and $b$.

The rate of delivery of tubular fluid (D) beyond site $a$ $\left(\mathrm{D}^{1} a_{a b}\right)$ during total collection from site $b$ (collection 1) was calculated from NFR measured during collection at site $b$ and the average $\mathrm{TF} / \mathrm{P}_{\mathrm{In}}$ measured at site $a$ during the second and third collections:

$$
\mathrm{D}^{1}{ }_{a \rightarrow b}=\mathrm{NFR}\left(\mathrm{P} / \mathrm{TF}_{1 \mathrm{n}}\right)_{a} \text {. }
$$

The rate of delivery beyond site $a$ during the double collection $\left(\mathrm{D}^{2}{ }_{a \rightarrow b}\right)$ was calculated from NFR (sum of collections at sites $a$ and $b$ ), concentrations of inulin in plasma and tubular fluid at site $a$ and the collection rate at site $a\left(\mathrm{~V}_{a}\right)$ :

$$
\mathrm{D}^{2}{ }_{a \rightarrow b}=\mathrm{NFR}\left(\mathrm{P} / \mathrm{TF}_{\mathrm{In}}\right)_{a}-\mathrm{V}_{a} .
$$

The absolute rate of reabsorption between sites $a$ and $b$ was calculated as $\mathrm{D}_{a \rightarrow b}$ minus the collection rate at site $b\left(\mathrm{~V}_{b}\right)$.

The extent of balance between tubular load and reabsorption was expressed as a percentage by dividing the percentage change in absolute reabsorption by the simultaneous percentage change in $\mathrm{D}_{a \rightarrow b}$.

These studies involved two micropuncturists operating simultaneously under a double dissecting microscope. The operators alternated sampling at early and late proximal tubular sites.

\section{RESULTS}

Details of this experiment are given in Table I. Total collections were made first from the last accessible proximal convolution (site $b$ ) during which time a second pipette was positioned in the lumen (but not aspirating) at one of the first accessible convolutions of the same tubule ( site $a$ ). During this first collection NFR averaged $43.5 \pm 13.9 \mathrm{nl} / \mathrm{min} ; \mathrm{TF} / \mathrm{P}$ inulin averaged 2.54 \pm 0.72 at site $b$ during this first collection, consistent with the visual evidence that site $b$ represented a late proximal convolution. Immediately after completing this first collection simultaneous collections were begun from site $a$ (collection $2 a$ ) and site $b$ (collection $2 b$ ). NFR during this double collection (collection $2 a+$ collection $2 b$ ) averaged $40.4 \pm 15.1 \mathrm{nl} / \mathrm{min}$ which was not statistically different $(P>0.05)$ from that measured during the initial total collection from site $b$. At the conclusion of the double collection a total collection was made at site $a$ only (collection 3 ) and this third measurement of NFR averaged $44.2 \pm 14.3 \mathrm{nl} / \mathrm{min}$ which was not statistically different from the previous two measurements in the same nephron (variance analysis, $P>0.05$ ). Thus, overall NFR was the same when measured by total collection from a late proximal convolution (site $b$ ), by combined collections from early and late proximal convolution (site $a+$ site $b$ ) or from an early convolution only (site $a$ ).

From the data obtained during the three collections it was possible to calculate the delivery of tubular fluid

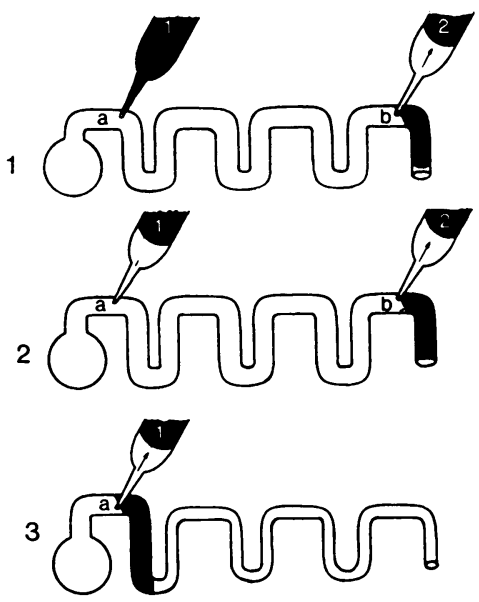

FIgURE 1 Technique for reducing intratubular flow rate by dual collection. (1) Pipette no. 1 was placed in an early proximal convolution $(a)$ and an oil droplet was injected to identify the last accessible proximal tubular convolution (b) where second pipette no. 2 was inserted. A total collection then was made at site $b$ only (collection 1 ). (2) Dual collections were then made by aspirating part of the tubular fluid at site $a$ and simultaneously collecting the remaining tubular fluid at site $b$ (collections $2 a$ and $2 b$ ). Finally, a total free-flow collection was made at site $a$ (collection 3).

between sites $a$ and $b$ of the proximal tubule, first when no fluid was aspirated at site $a$ and again when a partial collection was made at this site. When the flow of tubular fluid between sites $a$ and $b$ was unaltered, delivery (D) beyond site $a$ averaged $28.3 \pm 9.5 \mathrm{nl} / \mathrm{min}$ and reabsorption (C) between sites $a$ and $b$ averaged 9.4 $5.0 \mathrm{nl} / \mathrm{min}$. During partial aspiration at site $a$ delivery of tubular fluid beyond site $a$ was decreased to $15.2 \pm 6.6$ $\mathrm{nl} / \mathrm{min}$ and reabsorption between sites $a$ and $b$ decreased to $6.1 \pm 3.4 \mathrm{nl} / \mathrm{min}$. Thus, in the absence of a change in NFR a reduction in flow of tubular fluid averaging $46 \pm$ $15 \%$ was associated with a $29 \pm 30 \%$ reduction in the absolute rate of reabsorption. This represents $63 \%$ balance between load and reabsorption for the segments of proximal tubule in which delivery was decreased in the absence of a change in NFR.

As shown in Table I TF/ $/ \mathrm{P}_{1 n}$ at site $a$ was not statistically different during collection $2 a$ (partial collection) and collection 3 (total collection) which together with the measurements of NFR indicates that there was no significant effect of the procedure on volume delivery and fractional and absolute reabsorption up to the puncture site in the early proximal tubule. $\mathrm{TF} / \mathrm{P}_{1 n}$ at site $b$ (late proximal tubule) increased from $2.54 \pm 0.72$ during collection 1 (total collection from the late proximal tubule) to $2.98 \pm 0.99(P<0.01)$ during collection $2 b$ (reduced delivery between sites $a$ and $b$ ), indicating that the reduction in flow of tubular fluid between sites $a$ and $b$ was associated with some increase in fractional reab- 
TABLE I

Reabsorption by Segments of Proximal Tubule with and without a Reduction in Delivery of Tubular Filuid by Partial Collection

\begin{tabular}{|c|c|c|c|c|c|c|c|c|c|c|c|c|}
\hline \multirow[b]{2}{*}{ Animal } & \multicolumn{2}{|c|}{ NFR } & \multicolumn{2}{|c|}{$\left(\mathrm{TF} / \mathrm{P}_{\left.\mathrm{In}_{\mathrm{n}}\right)_{a}}\right.$} & \multicolumn{2}{|c|}{$\left(\mathrm{TF} / \mathrm{P}_{\mathrm{In}_{\mathrm{n}}}\right)_{b}$} & \multicolumn{2}{|c|}{$D_{a \rightarrow b}$} & \multicolumn{2}{|c|}{$\mathrm{C}_{a \rightarrow b}$} & \multirow[b]{2}{*}{$\Delta \mathrm{D}_{a \rightarrow b}$} & \multirow[b]{2}{*}{$\Delta \mathrm{C}_{a \rightarrow b}$} \\
\hline & 1 & 2 & $1^{*}$ & 2 & 1 & 2 & 1 & 2 & 1 & 2 & & \\
\hline \multicolumn{3}{|c|}{$n l / \min$} & & & & & \multicolumn{2}{|c|}{$n l / \min$} & \multicolumn{2}{|c|}{$n l / \min$} & $\%$ & $\%$ \\
\hline I & $\begin{array}{l}35.2 \\
36.0\end{array}$ & $\begin{array}{l}45.0 \\
31.2\end{array}$ & $\begin{array}{l}1.34 \\
1.59\end{array}$ & $\begin{array}{l}1.22 \\
1.41\end{array}$ & $\begin{array}{l}2.73 \\
1.68\end{array}$ & $\begin{array}{l}2.14 \\
1.73\end{array}$ & $\begin{array}{l}27.6 \\
24.1\end{array}$ & $\begin{array}{l}18.6 \\
13.1\end{array}$ & $\begin{array}{r}14.7 \\
2.5\end{array}$ & $\begin{array}{l}8.1 \\
2.4\end{array}$ & $\begin{array}{l}32.6 \\
45.6\end{array}$ & $\begin{array}{r}44.9 \\
4.0\end{array}$ \\
\hline II & $\begin{array}{l}31.2 \\
35.2 \\
42.8\end{array}$ & $\begin{array}{l}28.3 \\
40.2 \\
31.5\end{array}$ & $\begin{array}{l}\ddagger \\
1.79 \\
2.20\end{array}$ & $\begin{array}{l}1.61 \\
1.73 \\
2.48\end{array}$ & $\begin{array}{l}4.26 \\
2.86 \\
2.88\end{array}$ & $\begin{array}{l}5.67 \\
2.59 \\
3.54\end{array}$ & $\begin{array}{l}19.3 \\
20.1 \\
18.2\end{array}$ & $\begin{array}{r}11.7 \\
14.7 \\
5.9\end{array}$ & $\begin{array}{r}12.0 \\
7.8 \\
3.3\end{array}$ & $\begin{array}{l}8.3 \\
4.9 \\
1.7\end{array}$ & $\begin{array}{l}39.4 \\
26.9 \\
67.6\end{array}$ & $\begin{array}{l}30.8 \\
37.2 \\
48.5\end{array}$ \\
\hline III & $\begin{array}{l}41.6 \\
45.2 \\
41.2 \\
57.5 \\
51.0 \\
35.6\end{array}$ & $\begin{array}{l}35.8 \\
33.5 \\
45.3 \\
42.5 \\
41.7 \\
49.9\end{array}$ & $\begin{array}{l}1.35 \\
1.30 \\
1.09 \\
1.01 \\
1.86 \\
1.34\end{array}$ & $\begin{array}{l}1.50 \\
1.30 \\
1.24 \\
1.48 \\
1.49 \\
1.83\end{array}$ & $\begin{array}{l}2.20 \\
2.14 \\
1.70 \\
2.69 \\
2.05 \\
2.29\end{array}$ & $\begin{array}{l}2.63 \\
2.54 \\
2.12 \\
2.20 \\
2.21 \\
2.29\end{array}$ & $\begin{array}{l}29.3 \\
34.8 \\
35.6 \\
47.7 \\
30.9 \\
23.0\end{array}$ & $\begin{array}{l}13.4 \\
14.7 \\
20.5 \\
18.6 \\
16.1 \\
10.9\end{array}$ & $\begin{array}{r}10.4 \\
13.6 \\
11.4 \\
26.4 \\
6.0 \\
7.4\end{array}$ & $\begin{array}{l}5.8 \\
7.2 \\
8.6 \\
6.0 \\
5.3 \\
2.3\end{array}$ & $\begin{array}{l}54.3 \\
57.8 \\
42.4 \\
61.0 \\
47.9 \\
52.6\end{array}$ & $\begin{array}{l}44.2 \\
47.1 \\
24.6 \\
77.3 \\
11.7 \\
68.9\end{array}$ \\
\hline IV & 51.0 & 45.0 & 1.73 & 1.84 & 2.52 & 3.16 & 28.6 & 12.8 & 8.4 & 5.3 & 55.2 & 36.9 \\
\hline $\mathrm{V}$ & $\begin{array}{l}34.4 \\
36.9 \\
40.0 \\
47.5 \\
33.7 \\
24.6 \\
29.8 \\
15.9\end{array}$ & $\begin{array}{l}36.6 \\
37.0 \\
42.3 \\
39.1 \\
27.9 \\
30.3 \\
23.9 \\
12.0\end{array}$ & $\begin{array}{l}1.57 \\
1.32 \\
\ddagger \\
1.31 \\
1.29 \\
1.40 \\
1.13 \\
1.11\end{array}$ & $\begin{array}{l}1.70 \\
1.43 \\
1.41 \\
1.26 \\
1.37 \\
1.38 \\
1.17 \\
1.14\end{array}$ & $\begin{array}{l}3.06 \\
1.95 \\
1.69 \\
2.02 \\
2.15 \\
1.51 \\
2.20 \\
1.64\end{array}$ & $\begin{array}{l}3.65 \\
2.59 \\
1.92 \\
2.22 \\
1.83 \\
1.60 \\
1.94 \\
1.57\end{array}$ & $\begin{array}{l}21.2 \\
26.9 \\
28.4 \\
37.2 \\
25.4 \\
17.6 \\
25.9 \\
14.1\end{array}$ & $\begin{array}{r}13.2 \\
14.1 \\
22.8 \\
18.2 \\
16.8 \\
11.8 \\
9.6 \\
5.6\end{array}$ & $\begin{array}{r}10.0 \\
8.0 \\
4.8 \\
13.8 \\
9.8 \\
1.3 \\
12.4 \\
4.4\end{array}$ & $\begin{array}{l}7.1 \\
6.4 \\
6.1 \\
7.8 \\
4.2 \\
1.5 \\
3.9 \\
1.5\end{array}$ & $\begin{array}{l}37.7 \\
47.6 \\
19.7 \\
51.1 \\
33.9 \\
33.0 \\
62.9 \\
60.2\end{array}$ & $\begin{array}{r}29.0 \\
20.0 \\
-21.3 \\
43.5 \\
57.1 \\
-15.3 \\
68.5 \\
65.9\end{array}$ \\
\hline VI & $\begin{array}{l}68.7 \\
63.5 \\
28.1 \\
37.1\end{array}$ & $\begin{array}{l}44.5 \\
63.3 \\
24.7 \\
28.0\end{array}$ & $\begin{array}{l}1.77 \\
2.23 \\
1.41 \\
3.23\end{array}$ & $\begin{array}{l}1.81 \\
1.99 \\
1.60 \\
2.45\end{array}$ & $\begin{array}{l}3.20 \\
3.05 \\
2.52 \\
4.27\end{array}$ & $\begin{array}{l}2.90 \\
3.59 \\
3.98 \\
4.01\end{array}$ & $\begin{array}{l}37.8 \\
31.7 \\
18.8 \\
13.4\end{array}$ & $\begin{array}{r}13.0 \\
28.9 \\
10.0 \\
6.6\end{array}$ & $\begin{array}{r}16.3 \\
10.9 \\
7.7 \\
4.7\end{array}$ & $\begin{array}{r}4.9 \\
12.1 \\
6.0 \\
2.6\end{array}$ & $\begin{array}{r}65.6 \\
8.8 \\
46.8 \\
44.7\end{array}$ & $\begin{array}{r}69.9 \\
-11.0 \\
22.0 \\
50.7\end{array}$ \\
\hline VII & $\begin{array}{l}48.6 \\
54.8 \\
43.4 \\
77.2 \\
46.0\end{array}$ & $\begin{array}{l}39.8 \\
58.7 \\
47.7 \\
84.9 \\
41.5\end{array}$ & $\begin{array}{l}1.12 \\
\ddagger \\
1.47 \\
1.42 \\
\ddagger\end{array}$ & $\begin{array}{l}1.20 \\
1.39 \\
1.37 \\
1.50 \\
2.21\end{array}$ & $\begin{array}{l}1.63 \\
2.15 \\
2.03 \\
1.96 \\
2.49\end{array}$ & $\begin{array}{l}2.67 \\
2.77 \\
2.90 \\
2.56 \\
2.70\end{array}$ & $\begin{array}{l}41.8 \\
39.5 \\
30.6 \\
53.3 \\
20.7\end{array}$ & $\begin{array}{r}8.8 \\
24.6 \\
13.4 \\
35.3 \\
11.4\end{array}$ & $\begin{array}{r}12.1 \\
14.0 \\
9.2 \\
13.8 \\
2.2\end{array}$ & $\begin{array}{r}4.7 \\
12.3 \\
7.0 \\
14.9 \\
2.0\end{array}$ & $\begin{array}{l}78.9 \\
37.7 \\
56.2 \\
33.4 \\
44.9\end{array}$ & $\begin{array}{r}61.1 \\
12.1 \\
23.9 \\
-8.0 \\
9.0\end{array}$ \\
\hline VIII & $\begin{array}{l}54.4 \\
62.6 \\
58.9 \\
52.8 \\
56.6\end{array}$ & $\begin{array}{l}53.2 \\
62.3 \\
56.3 \\
51.4 \\
51.0\end{array}$ & $\begin{array}{l}\ddagger \\
1.93 \\
2.13 \\
\ddagger \\
1.39\end{array}$ & $\begin{array}{l}2.77 \\
1.85 \\
2.26 \\
1.92 \\
1.66\end{array}$ & $\begin{array}{l}3.13 \\
3.23 \\
2.42 \\
2.84 \\
2.10\end{array}$ & $\begin{array}{l}3.28 \\
3.85 \\
2.66 \\
3.28 \\
2.83\end{array}$ & $\begin{array}{l}20.9 \\
33.2 \\
27.1 \\
28.0 \\
37.4\end{array}$ & $\begin{array}{l}10.5 \\
22.7 \\
16.5 \\
19.2 \\
17.6\end{array}$ & $\begin{array}{r}3.5 \\
13.8 \\
2.8 \\
9.4 \\
10.5\end{array}$ & $\begin{array}{r}1.6 \\
11.8 \\
2.8 \\
7.9 \\
7.2\end{array}$ & $\begin{array}{l}49.7 \\
31.6 \\
39.1 \\
31.4 \\
52.9\end{array}$ & $\begin{array}{r}54.2 \\
14.5 \\
0.0 \\
15.6 \\
31.4\end{array}$ \\
\hline IX & $\begin{array}{l}53.2 \\
68.9\end{array}$ & $\begin{array}{l}59.4 \\
48.2\end{array}$ & $\begin{array}{l}1.43 \\
\ddagger\end{array}$ & $\begin{array}{l}1.70 \\
1.52\end{array}$ & $\begin{array}{l}2.47 \\
2.75\end{array}$ & $\begin{array}{l}3.29 \\
2.45\end{array}$ & $\begin{array}{l}34.4 \\
45.5\end{array}$ & $\begin{array}{l}14.1 \\
25.2\end{array}$ & $\begin{array}{l}12.9 \\
20.4\end{array}$ & $\begin{array}{l}6.9 \\
9.6\end{array}$ & $\begin{array}{l}59.0 \\
44.6\end{array}$ & $\begin{array}{l}46.5 \\
52.9\end{array}$ \\
\hline $\mathrm{X}$ & $\begin{array}{l}40.4 \\
70.0 \\
43.4\end{array}$ & $\begin{array}{l}40.0 \\
71.5 \\
58.0\end{array}$ & $\begin{array}{l}\ddagger \\
\ddagger \\
\ddagger \\
\ddagger\end{array}$ & $\begin{array}{l}1.42 \\
1.78 \\
2.01\end{array}$ & $\begin{array}{l}1.96 \\
2.43 \\
2.23\end{array}$ & $\begin{array}{l}2.04 \\
3.37 \\
3.03\end{array}$ & $\begin{array}{l}28.3 \\
39.2 \\
21.7\end{array}$ & $\begin{array}{r}16.8 \\
27.6 \\
9.2\end{array}$ & $\begin{array}{r}7.7 \\
10.3 \\
2.2\end{array}$ & $\begin{array}{r}5.0 \\
13.0 \\
3.2\end{array}$ & $\begin{array}{l}40.1 \\
29.6 \\
57.6\end{array}$ & $\begin{array}{r}35.1 \\
-26.2 \\
-45.5\end{array}$ \\
\hline XI & $\begin{array}{l}32.3 \\
30.2 \\
28.2\end{array}$ & $\begin{array}{l}28.3 \\
19.9 \\
18.0\end{array}$ & $\begin{array}{l}\ddagger \\
1.89 \\
2.73\end{array}$ & $\begin{array}{l}1.64 \\
2.17 \\
1.94\end{array}$ & $\begin{array}{l}3.10 \\
4.28 \\
4.09\end{array}$ & $\begin{array}{l}4.97 \\
5.67 \\
4.75\end{array}$ & $\begin{array}{l}23.4 \\
15.0 \\
12.4\end{array}$ & $\begin{array}{r}15.8 \\
3.3 \\
6.3\end{array}$ & $\begin{array}{l}9.3 \\
7.9 \\
5.5\end{array}$ & $\begin{array}{r}10.6 \\
2.1 \\
3.7\end{array}$ & $\begin{array}{l}19.8 \\
78.0 \\
49.0\end{array}$ & $\begin{array}{r}-13.9 \\
73.4 \\
32.0\end{array}$ \\
\hline $\begin{array}{l}\text { Means } \\
\text { SD } \\
n \\
P\end{array}$ & $\begin{array}{c}43.5 \\
\pm 13.9 \\
42 \\
\langle 0.1\rangle\end{array}$ & $\begin{array}{r}40.4 \\
\pm 15.1 \\
\\
0.05\end{array}$ & $\begin{array}{r}1.60 \\
\pm 0.48 \\
\end{array}$ & $\begin{array}{r}1.67 \\
\pm 0.38 \\
.70\end{array}$ & $\begin{array}{r}2.54 \\
\pm 0.72\end{array}$ & $\begin{array}{r}2.98 \\
\pm 0.99 \\
.01\end{array}$ & $\begin{array}{r}28.3 \\
\pm 9.5\end{array}$ & $\begin{array}{r}15.2 \\
\pm 6.6 \\
001\end{array}$ & $\begin{array}{r}9.4 \\
\pm 5.0\end{array}$ & $\begin{array}{r}6.1 \\
\pm 3.4 \\
001\end{array}$ & $\begin{array}{r}45.0 \\
\pm 15.0\end{array}$ & $\begin{array}{r}29.0 \\
\pm 29.8\end{array}$ \\
\hline
\end{tabular}

Roman numerals in the first column represent different animals. Each row of data represents single nephrons which are shown in the sequence in which they are studied. Abbreviations are as follows: NFR, nephron filtration rate; $\left(T F / P_{I_{n}}\right)_{a}$, ratio of inulin in tubular fluid collected at site $a$ (early proximal tubule) to that in plasma; $\left(\mathrm{TF} / \mathrm{P}_{\mathrm{In}}\right)_{b}$, ratio of inulin in tubular fluid collected at site $b$ (late proximal tubule) to that in plasma; $\mathrm{D}_{a \rightarrow b}$, volume of tubular fluid delivered between sites $a$ and $b$; $\mathrm{C}_{a \rightarrow b}$, absolute rate of reabsorption between sites $a$ and $b ; 1$ refers to initial total collection at site $b, 2$ refers to the dual collections at sites $a$ and $b$.

* The control (1) values for $\left(\mathrm{TF} / \mathrm{P}_{\mathrm{In}}\right)_{a}$ were determined from the final total free-flow collection at site $a$ (see Methods).

$\ddagger$ Final total collection at site $a$ (collection 3 ) was not performed. 
sorption by these segments of proximal tubules. This increased fractional reabsorption at the late proximal tubule sites is similar to that observed in the late proximal tubule when NFR and whole kidney filtration are reduced approximately $50 \%$ (23) by aortic constriction, indicating incomplete glomerulotubular balance under both circumstances.

\section{DISCUSSION}

The purpose of the present experiment was to reexamine the possibility that changes in the volume of filtrate per se will result in directionally similar changes in the rate of proximal tubular reabsorption. The reasons for reinvestigating this question were: (a) Although previous theories regarding an intraluminal pathway for glomerulotubular balance have not withstood rigorous experimental testing, other intraluminal pathways not yet investigated are possible. (b) There is a large body of evidence that capillary forces can influence proximal tubular reabsorption $(13-20,24-26)$; such evidence, together with the lack of experimental support for other mechanisms of glomerulotubular balance has shifted attention to peritubular forces as the pathway coupling filtration rate and reabsorption. (c) Independent of the exact mechanism involved, the most direct evidence against an intraluminal coupling of load and reabsorption derives from in vivo microperfusion studies in which it was concluded that perfusion rate had little or no effect on reabsorptive rate (9-12). However, in other microperfusion studies $(8,10,13)$ a variable effect of load on reabsorptive rate has been observed. In an extensive re-examination of the in vivo microperfusion technique (21) we observed that the rate of reabsorption of an artificial perfusion solution, such as that usually used, declines after a brief period of perfusion, whereas reabsorption of an ultrafiltrate of plasma remains constant over the same period of time. This observation alone raises the possibility that reabsorption of sodium may be coupled to some unidentified filterable constituents of plasma. Moreover, the experimental error involved in measuring reabsorptive rates by microperfusion of necessarily short tubular segments is so great that important changes in reabsorption could go undetected. When only longer tubular segments perfused with an ultrafiltrate of plasma were examined a statistically significant relationship existed between perfusion rate and the rate of reabsorption (21).

For these reasons we deemed it important to reexamine the relationship between intraluminal load and tubular reabsorption using an experimental design that would permit manipulation of delivery of normal glomerular filtrate in individual tubules in the absence of hemodynamic changes. This was accomplished by puncturing the same proximal tubule at both the most proxi- mal and most distal sites accessible on the surface. Measurements were made first by total collections of tubular fluid only from the distal site and then again during continuous partial aspiration through the proximally placed pipette. This method permitted changing the delivery of filtrate within the tubular segment lying between the two collecting pipettes without directly manipulating NFR. In these studies there was no significant change in NFR when delivery of tubular fluid between the two puncture sites was decreased an average of $46 \%$. In association with this decreased delivery the rate of reabsorption fell $29 \%$, indicating $63 \%$ balance between load and reabsorption. Therefore, the fall in reabsorption as delivery between the pipettes was reduced must have been due to some effect of the reduction in intraluminal load per se.

The mechanism whereby decreased intraluminal load may lead to a fall in proximal tubular reabsorption remains unknown. It seems unlikely that this relationship could be due to an effect of tubular distension on reabsorption as suggested by Gertz et al. (4). It has been shown that during obstruction of individual tubules (12, $27)$, as well as during partial ureteral obstruction $(6,7)$, reabsorption fell at a time when tubular diameter was increased. We have made similar observations in this laboratory. ${ }^{3}$ Also, it seems unlikely that the coupling of load and reabsorption is mediated by an effect of delivery out of the proximal tubule to activate a feedback mechanism such as suggested by Leyssac (2). In the present studies reabsorption changed as load in the proximal tubule changed even though flow beyond the proximal tubule was interrupted throughout. Thus, even though the present results support the view that glomerulotubular balance can be largely a result of changes in intraluminal load per se they do not support either of these previously proposed pathways.

Although it is unlikely that diffusion of sodium within the lumen of the tubule constitutes a limiting step in sodium reabsorption it does seem possible that the concentration of sodium might decrease and that of unreabsorbed solutes increase in unstirred layers adjacent to the apical cell membrane, especially within the crypts of microvilli. Such a fall in sodium concentration and rise in the concentration of unreabsorbed solute could limit the rate of net reabsorption due to the limited access for diffusion from lumen into the crypts between microvilli (28). Increasing flow rate of tubular fluid might increase mixing of this unstirred diffusion barrier and thereby enhance sodium reabsorption by increasing diffusion of sodium into cells. This proposal is similar to that of Kelman (1) except the poorly mixed barrier to diffusion would be within the brush border rather

\footnotetext{
${ }^{3}$ Bartoli, E., J. Conger, and I. E. Earley. Unpublished results.
} 
than within the tubular lumen. This interpretation is consistent with the report that unidirectional fluxes from lumen to blood of labeled $\mathrm{Na}, \mathrm{Cl}$, and urea are flow dependent (29).

Net reabsorption conceivably could change in direct relationship with the volume of filtrate if sodium reabsorption were dependent upon, or secondary to, the reabsorption of some other constituent of plasma. For instance, if sodium and water reabsorption were driven by the reabsorption of some other substance and if this substance could be reabsorbed only to some limiting minimal concentration, then a reduction in filtration rate would automatically reduce the amount of this hypothetical substance filtered and reabsorbed and the fractional reabsorption of sodium and water would remain constant. In agreement with this possibility it has been shown recently that potential differences across the proximal tubular epithelium are affected by glucose and amino acids (30). The present studies provide no evidence as to how changes in intraluminal load may influence reabsorption and these suggestions are offered only as possibilities worthy of further consideration.

These results and conclusions should not be regarded as evidence against a role of peritubular capillary absorption in the regulation of sodium and water reabsorption or even in the phenomenon of glomerulotubular balance. The degree of balance between intraluminal load and reabsorption was not as complete in this study as is the degree of glomerulotubular balance during a reduction in renal perfusion pressure (23). It may be that intraluminal factors operate together with peritubular factors $(14-20,24-26)$ to effect an optimal degree of coupling between load and reabsorption. Also, peritubular and other factors may determine a level of reabsorption on which background intraluminal factors operate to maintain relatively constant fractional reabsorption when filtration rate changes.

\section{ACKNOWLEDGMENTS}

The authors are grateful to Monika Mueller and Randall Hake for their assistance with these studies.

These studies were supported by Grants AM 12753, AM 05670, and AM 16187-01 from the National Institutes of Health and NGR 05-025-007 from the National Aeronautics and Space Administration.

\section{REFERENCES}

1. Kelman, R. B 1962. A theoretical note on exponential flow in the proximal part of the mammalian nephron. Bull. Math. Biophys. 24: 303.

2. Leyssac, P. P. 1965. The in vivo effect of angiotensin and noradrenaline on the proximal tubular reabsorption of salt in mammalian kidneys. Acta. Physiol. Scand. $64: 167$.

3. Bartoli, E., and L. E. Earley. 1971. The relative contributions of reabsorptive rate and redistributed nephron filtration rate to changes in proximal tubular fractional reabsorption during acute saline infusion and aortic constriction in the rat. J. Clin. Invest. 50: 2191.

4. Gertz, K. H., J. A. Mangos, G. Braun, and H. D. Pagel. 1965. On the glomerular tubular balance in the rat kidney. Pfluegers Arch. $285: 360$.

5. Gertz, K. H. 1963. Transtubulare Natriumchloridflusse und Permeabilitat fur Nichtelektrolyte im proximalen und distalen Konvolut der Rattenniere. Pfluegers Arch. 276: 336 .

6. Brenner, B. M., C. M. Bennett, and R. W. Berliner. 1968. The relationship between glomerular filtration rate and sodium reabsorption by the proximal tubule of the rat nephron. J. Clin. Invest. $47: 1358$.

7. Rodicio, J., J. Herrera-Acosta, J. C. Sellman, F. C. Rector, Jr., and D. W. Seldin. 1969. Studies on glomerulotubular balance during aortic constriction, ureteral obstruction and venous occlusion in hydropenic and saline-loaded rats. Nephron. $6: 437$.

8. Wiederholt, M., K. Hierholzer, E. E. Windhager, and G. Giebisch. 1967. Microperfusion study of fluid reabsorption in proximal tubules of rat kidneys. Am. J. Physiol. 213: 809.

9. Morgan, T., and R. W. Berliner. 1969. In vivo perfusion of proximal tubules of the rat: glomerulotubular balance. Am. J. Physiol. 217: 992.

10. Radtke, H. W., G. Rumrich, S. Klon, and K. J. Ullrich. 1971. Influence of luminal diameter and flow velocity on the isotonic fluid absorption and ${ }^{38} \mathrm{C} 1$ permeability of the proximal convolution of the rat kidney. Pfluegers Arch. 324: 228.

11. Morel, F., and Y. Murayama. 1970. Simultaneous measurement of undirectional and net sodium fluxes in microperfused rat proximal tubules. Pfluegers Arch. 320: 1.

12. Burg, M. D., and J. Orloff. 1968. Control of fluid absorption in the renal proximal tubule. J. Clin. Invest. 47: 2016.

13. Buentig, W. E., and L. E. Earley. 1971. Demonstration of independent roles of proximal tubular reabsorption and intratubular load in the phenomenon of glomerulotubular balance during aortic constriction in the rat. J. Clin. Invest. $50: 77$.

14. Earley, L. E., and R. M. Friedler. 1965. Studies on the mechanism of natriuresis accompanying increased renal blood flow and its role in the renal response to extracellular volume expansion. J. Clin. Invest. 44: 1857.

15. Martino, J. A., and L. E. Earley. 1967. Demonstration of a role of physical factors as determinants of the natriuretic response to volume expansion. J. Clin. Invest. 46: 1963.

16. Lewy, J. E., and E. E. Windhager. 1968. Peritubular control of proximal tubular fluid reabsorption in the rat kidney. Am. J. Physiol. 214: 943.

17. Windhager, E. E., J. E. Lewy, and A. Spitzer. 1969. Intrarenal control of proximal tubular reabsorption of sodium and water. Nephron. 6: 247.

18. Brenner, B. M., and J. L. Troy. 1971. Postglomerular vascular protein concentration: evidence for a causal role in governing fluid reabsorption and glomerulotubular balance by the renal proximal tubule. J. Clin. Invest. 50: 336 .

19. Brenner, B. M., K. H. Falchuk, R. I. Keimowitz, and R. W. Berliner. 1969. The relationship between peritubular capillary protein concentration and fluid reabsorption by the renal proximal tubule. J. Clin. Invest. $48: 1519$. 
20. Daugharty, T. M., S. M. Zweig, and L. E. Earley. 1971. Assessment of renal hemodynamic factors in whole kidney glomerulotubular balance. Am. J. Physiol. 220: 2021.

21. Bartoli, E., and L. E. Earley. Importance of ultrafilterable plasma factors in maintaining tubular reabsorption. Kidney International. In press.

22. Snedecor, G. W., and W. G. Cochran. 1937. Statistical Methods. Iowa State University Press, Ames. 6th edition.

23. Bartoli, E., and L. E. Earley. 1972. Effects of saline infusion on glomerulotubular balance. Kidney International. $1: 67$.

24. Imai, M., and J. P. Kokko. 1972. Effect of peritubular protein concentration on reabsorption of sodium and water in isolated perfused proximal tubules. J. Clin. Invest. $51: 314$.

25. Welling, L. W., and J. J. Grantham. 1972. Physical properties of isolated perfused renal tubules and tubular basement membranes. J. Clin. Invest. 51: 1063.
26. Grantham, J. J., P. B. Qualizza, and L. W. Welling. 1972. Influence of serum protein on net fluid reabsorption of isolated proximal tubules. Kidney International. 2: 66 .

27. Schnermann, J., D. Z. Levine, and M. Horster. 1969. A direct evaluation of the Gertz hypothesis on single rat proximal tubules in vivo: failure of the tubular volume to be the sole determinant of the reabsorptive rate. Pfluegers Arch. 308: 149.

28. Richardson, I. W., V. Ličko, and E. Bartoli. The nature of passive flows through tightly folded membranes (the influence of microstructure). J. Membrane Biol. In press.

29. Imai, M., and J. P. Kokko. 1971. Flow dependence of proximal tubular permeabilities for ${ }^{22} \mathrm{Na},{ }^{36} \mathrm{Cl}$ and ${ }^{14} \mathrm{C}$ urea. 5th Annual Meeting of the American Society of Nephrology. 1: 34. (Abstr.)

30. Kokko, J. P. 1972. Proximal tubular potential differences: dependence on glucose, $\mathrm{HCO}_{3}$ and amino acids. Clin. Res. 20: 598. (Abstr.) 